Clinical Skills in Nursing 
Also by Maggie Nicol (with Jane Dacre):

Clinical Skills: The Learning Matrix for Students of Medicine and Nursing (Radcliffe Medical Press, 1996) 


\title{
Clinical Skills in Nursing
}

\section{The return of the practical room?}

\author{
Edited by
}

\author{
Maggie Nicol \\ and
}

Sally Glen 


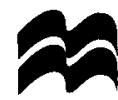

(C) Selection, editorial matter, Chapter 8: Maggie Nicol and Sally Glen, 1999

(C) Foreword: Anne Jarvie, 1999

(C) Other chapters in order: Sally Glen; Maggie Nicol; Beryl Howard; Maggie Nicol and Carol Bavin; Sally Glen and Iain McA Ledingham; Isabelle Whaite, Rose Allen and Dorothy Jones; Karen Veitch, 1999

All rights reserved. No reproduction, copy or transmission of this publication may be made without written permission.

No paragraph of this publication may be reproduced, copied or transmitted save with written permission or in accordance with the provisions of the Copyright, Designs and Patents Act 1988, or under the terms of any licence permitting limited copying issued by the Copyright Licensing Agency Limited, 90 Tottenham Court Road, London W1P 9HE.

Any person who does any unauthorised act in relation to this publication may be liable to criminal prosecution and civil claims for damages.

The authors have asserted their right to be identified as the authors of this work in accordance with the Copyright, Designs and Patents Act 1988.

First published 1999 by

MACMILLAN PRESS LTD

Houndmills, Basingstoke, Hampshire RG21 6XS

and London

Companies and representatives throughout the world

ISBN 978-0-333-72614-3 ISBN 978-1-349-14724-3 (eBook)

DOI 10.1007/978-1-349-14724-3

A catalogue record for this book is available

from the British Library.

This book is printed on paper suitable for recycling and made from fully managed and sustained forest sources.

$\begin{array}{llllllllll}10 & 9 & 8 & 7 & 6 & 5 & 4 & 3 & 2 & 1\end{array}$

$\begin{array}{llllllllll}08 & 07 & 06 & 05 & 04 & 03 & 02 & 01 & 00 & 99\end{array}$

Editing and origination by

Aardvark Editorial, Mendham, Suffolk 


\section{Contents}

Foreword:

List of Contributors

xii

Preface: Maggie Nicol and Sally Glen

ix

xiii

1 The Demise of the Apprenticeship Model 1

Sally Glen

Introduction

Apprenticeship-type approaches

Self-directed approaches

The advent of the diploma

'Fitness for purpose'

Placement experience

Changing context of nurse education

Changing environment of practitioners

Conclusion

References

2 Is Simulation the Answer?

Maggie Nicol

Introduction

What is simulation?

Advantages of simulation

Disadvantages of simulation

Conclusion

References

3 Development of a Skills Centre 25

Beryl Howard

Introduction $\quad 25$

Context 25

Introduction of skills teaching into the curriculum 26

Key staff

Practical room recycled? $\quad 29$

Resourcing issues $\quad 30$

Teaching and learning strategies $\quad 30$

Staff development 31 
Integration and scheduling of the workshops into the curriculum

Assessment of competence - Objective Structured

Clinical Examination (OSCE)

Benefits of the OSCE

Future developments

Conclusion

References

4 Teaching, Learning and Assessment Strategies

Maggie Nicol and Carol Bavin

Introduction

The Skills Centre at St Bartholomew's $\quad 40$

Teaching and learning strategies 41

Module A caring skills workbook $\quad 42$

Independent access by students $\quad 44$

$\begin{array}{ll}\text { Video production } & 46\end{array}$

Assessment of clinical skills $\quad 47$

Module A OSCE $\quad 47$

Module B OSCE $\quad 49$

Branch programme OSCE $\quad 51$

Interprofessional education 51

Conclusion $\quad 52$

References $\quad 53$

5 A Healthcare Network Approach $\quad 54$

Sally Glen and Iain McA Ledingham

Introduction $\quad 54$

Local determinants at The University of Dundee $\quad 55$

The Healthcare Learning Network 56

Clinical skills facility $\quad 57$

Learning opportunities $\quad 58$

Aims of the Healthcare Learning Network $\quad 59$

Computer-assisted learning $\quad 60$

Assessment of students $\quad 61$

Simulated patients $\quad 62$

Evaluation of the Network $\quad 62$

Future developments $\quad 63$

Conclusion $\quad 63$

References 64 
6 A Portfolio Approach

Isabelle Whaite, Rose Allen and Dorothy Jones

Introduction

65

Key values

65

Competence

67

Clinical assessment

68

The Portfolio

69

The Learning Contract

Core transferable skills

Clinical Skills Schedule

Structured approach

75

Conclusion

References

7 The Challenge of Primary Care

Karen Veitch

Introduction $\quad 82$

Rationale $\quad 83$

Development and implementation $\quad 86$

$\begin{array}{ll}\text { Educational resources } & 87\end{array}$

Personnel $\quad 89$

Facilities $\quad 90$

Advantages of the Skills Laboratory 91

Clinical skills $\quad 92$

Evaluation of the Skills Laboratory $\quad 93$

Future developments $\quad 94$

References $\quad 95$

8 The Way Forward $\quad 96$

Sally Glen and Maggie Nicol

'Fitness for purpose' 96

Balancing academic and clinical needs $\quad 98$

The role of the nurse lecturer 98

Developing life-long learners $\quad 99$

Multiprofessional practice $\quad 101$

Virtual skills learning $\quad 102$

References 103 


\section{List of Contributors}

Rosemary Allen MSc, BSc(Hons), DipN (Part A), RNT, RCNT, RGN is a Senior Lecturer within the Faculty of Health, University of Central Lancashire.

Carol Bavin RGN, RM, RCNT, DN is a Lecturer at St Bartholomew School of Nursing and Midwifery, City University, London.

Sally Glen MA(Ed), MA(Philosophy), DipEd(Lond), DipNEd, DN(Lond), RN, RSCN, RNT is Professor of Nursing Education, Dean of School of Nursing and Midwifery, University of Dundee.

Beryl Howard RN, MSc(Nurs), DipN(Lond), RCNT, RNT is Director of Pre-Registration Education at the Department of Nursing, Faculty of Healthcare and Social Work Studies, University of Salford.

Dorothy Jones MA, BEd(Hons), RNT, RN is Principal Lecturer at the Department of Primary and Community Nursing, University of Central Lancashire.

Iain McA Ledingham MBChB, MD(Hons), FRCS(Edin), FRCP(Edin/Glas), FInstBiol, FCCM, FRSE is Professor of Medical Education, Director of Clinical Skills Centre, Medical School, University of Dundee.

Maggie Nicol BSc(Hons), MSc, RGN, DN, PGDip(Ed) is a Senior Lecturer in Clinical Skills at St Bartholomew School of Nursing and Midwifery, City University, London.

Karen Veitch MSc, BSc, RGN, DN is a Practice Development Co-ordinator at the Primary Care Development Centre, Newcastle Upon Tyne.

Isabelle Whaite MA, DPSN, CertEd, RN, RM, RNT is a Principal Lecturer at the Faculty of Health, University of Central Lancashire. 


\section{Foreword}

The past decade has seen a growing interest in the teaching and learning of clinical nursing skills by students, practitioners, nurse teachers, managers and policy makers.

Despite methodological differences, it is striking that similar themes and issues are emerging from the numerous evaluation studies carried out since the introduction of the Project 2000 pre-registration programmes in the UK. These are notably in the area of clinical skills acquisition and show that newly qualified nurses often lack competence in what are frequently basic, fundamental nursing skills. Clinical skills acquisition is, of course, an essential prerequisite for registration as a nurse and this state of what Luker et al. (1966) ${ }^{1}$ refer to as 'practical skills illiteracy' is untenable.

In order to prepare future practitioners who are able to function effectively in a variety of healthcare settings, students now gain experience in a wide range of hospital and community placements. However, this means that they spend less time in a hospital ward setting, where students have traditionally developed and practised their skills. As nurse educators and healthcare providers struggle to identify sufficient quality clinical placements for increasingly large numbers of students, it is vital that students do not waste valuable clinical time learning how to perform fundamental nursing skills. That time should be spent practising and perfecting those skills, caring for real patients and clients with very real needs.

As the authors of this book argue, it is no longer sufficient to rely on students acquiring clinical skills by unstructured exposure in the placement. Skills teaching must be planned into the curriculum in order to prepare students for their placements so that they can optimise their learning within the context of an increasingly scarce and finite resource.

It is perhaps time, as the title of this book suggests, to reflect on the wisdom of removing the practical room from the educational base. Although at the time it appeared educationally sound to redirect the teaching of clinical skills to the patient at the bedside, it would seem that insufficient planning was under- 
taken to ensure that essential skills would be taught. With hindsight, it is interesting to note that nursing chose to eschew the virtues of simulation at a time when other practice disciplines, notably airline pilots, were looking to the virtual reality of simulators to hone their skills. The concurrent demise of the clinical teacher role and the increase in the academic workload of the nurse teacher has left practitioners with a heavy responsibility for skills acquisition and assessment of competence.

This book examines the use of simulation in skills teaching and the introduction of a new kind of practical room, the clinical skills laboratory. With memories of run-down practical rooms full of out-of-date equipment still fresh in many people's minds, this may be viewed as a retrograde step. However, as this book illustrates, modern clinical skills laboratories are not simply a re-introduction of the practical room. They seek to provide a realistic simulation of clinical practice with up-todate clinical equipment, opportunities for self-directed access by students, video recording and playback facilities, an appropriate environment for realistic campus-based practical examinations, and opportunities for shared learning with other healthcare students. Used creatively by clinically competent academic staff in the ways described in this book, skills laboratories will undoubtedly play an important part in the development of healthcare professionals of the future.

I am also pleased with the emphasis on shared learning with other clinicians. Healthcare is very much about teamwork, cooperation and collaboration. This needs to begin in the classroom or, rather, the skills laboratory. But clearly the skills laboratory is not a resource that should be restricted to the use of pre-registration students. The skills laboratory also has much to offer to continuing professional education and specialist training.

I commend this book to all involved in the education and training of healthcare professionals, be they academics, clinicians or managers. It is indeed timely and much needed.

ANNE JARVIE Chief Nursing Officer

1 Luker, K., Carlisle, C., Riley, E., Stitwell, J., Davies C. and Wilson. R. (1966) Project 2000 Fitness for Purpose, Report to the Department of Health, University of Liverpool and University of Warwick. 


\section{Preface}

The move to Diploma-level education that was achieved with the introduction of Project 2000 has resulted in less time being spent in clinical placements learning the art and science of nursing. Clinical experience now extends into homes, factories, schools, shops and community agencies. Although the integration of Colleges of Nursing and Midwifery into universities has undoubtedly invigorated the academic emphasis, it has also led to concerns that newly qualified nurses are no longer being equipped with the clinical skills that they need to fulfil their professional role. The aim of this book is to bring together current experience and future developments in clinical skills teaching and learning, in particular the use of simulation and nursing skills laboratories. It is intended to offer ideas and practical guidance to those developing curricula in the changing climate of health and social care provision.

Chapter 1 contextualises the debate related to clinical skills acquisition by exploring the shift away from the traditional apprentice-type model to a more education-led model of nurse education. One response to the reduced exposure to real patients and clients is to re-introduce the notion of the practical room and the use of simulated clinical practice to enable students to develop fundamental nursing skills. Chapter 2 examines the strengths and limitations of the use of simulation and its potential application to nurse education. Chapter 3 describes how one school strengthened skills learning in the curriculum, and outlines the development of a Clinical Skills Centre. The discussion focuses on practical issues such as the identification of resources; teaching, learning and assessment strategies; and staff development issues.

In Chapter 4, the authors highlight the opportunities for shared learning between nursing and medical students that are made possible by the development of an interprofessional skills teaching facility. The way in which student self-directed learning in the Skills Centre is supported by 'in-house' instruc- 
tional videos and workbooks, and the assessment of clinical skills using the Objective Structured Clinical Examination are also discussed.

Chapter 5 describes the ongoing development, implementation and evaluation of a multiprofessional Healthcare Learning Network. The concept is based on the premise that the development of knowledge, skills and attitudes is no longer bound in time and place but can occur at any time from any place. The Healthcare Learning Network is designed as a centre for learning with access and connectivity to resources well beyond the traditional physical constraints of a single building. The recruitment and training of members of the public to act as simulated patients to enable nursing, medical and other healthcare students to develop practical skills and problem identification and problem-solving abilities is also discussed.

Chapter 6 emphasises the importance of facilitating the integration of theory and practice through assessment strategies. The authors describe the use of a Portfolio as a tool for guiding and supporting learning in practice in order to develop professional competence. They describe how the Portfolio has provided a structured approach to skills teaching and learning that takes account of the reality of clinical practice. Chapter 7 expands the debate to include primary care personnel by describing an innovative resource centre designed to support and facilitate professional working in primary care. The author describes how the Skills Laboratory, which is part of the centre, helps primary care practitioners to address the difficulties experienced in clinical practice, such as acquiring specific technical skills, the organisation of training facilities and the provision of equipment. In the final chapter, the editors explore some issues currently influencing nurse education, for example the need to balance academic and clinical needs; the demand for multiprofessional education and practice; and the need to reconceptualise the role of the nurse lecturer.

MAGGIE NiGol City University SALLY GLen University of Dundee 